\section{Serial CS presentation and shuttlebox avoidance conditioning: A further look at the tendency to delay responding}

\author{
DONALD J. LEVIS* \\ University of Iowa. Iowa City, lowa 52240
}

Two experiments were reported. The first compared the effects of nonserial and serial (e.g., S1 followed by S2) CS presentations, while the second study compared nonserial and serial compound (e.g., S1 followed by S1 and S2) CS presentations on the acquisition of rats' avoidance responses in a shuttlebox situation. The avoidance-response latencies of Ss presented the serial CS conditions tended to be delayed until after the onset of the last stimulus segment introduced in to the sequence. This was not the case for the nonserial Ss who tended to avoid shortly after the onset of the CS-US interval. The delay in responding noted for the serial CS Ss occurred when either two or three stimuli comprised the sequence and when either serial or serjal compound presentation was employed. Serial compound conditions increased avoidance responding, but the serial condition did not. Other effects of CS complexity on avoidance responding were also reported.

As Razran (1965) noted, empirical codification of principles of compound-stimulus conditioning is a relatively unexplored parameter in America. The identification of such principles are important to a variety of areas including sensory preconditioning, higher-order conditioning, discrimination learning, and even psychotherapy (see Stampfl \& Levis, 1967).

In a recent study, Levis \& Stampfl (in press) explored the role of serial or sequential CS presentation (e.g., lights followed by tone) with albino rats in a shuttlebox situation. In the first experiment these investigators presented within a $16-\mathrm{sec}$ CS.US interval a one-component CS stimulus (S1), a two-component simultaneous compound (S1S2), a two-component serial (S1/S2) in which the first stimulus (S1) terminated at the midpoint of the CS-US interval and the onset of the second stimulus (S2) immediately followed the termination of $\mathrm{S} 1$, and a two-component serial compound (S1/S1S2) that consisted of a single stimulus (S1) for the first half of the CS-US interval and two stimuli (S1 plus S2) for the latter half of the CS-US interval. A major finding of this study was that the time characteristics of the avoidance response differed between the nonserial (S1, S1S2) and serial (S1/S2, S1/S1S2) CS conditions. A breakdown of the avoidance responses into $1-\mathrm{sec}$ class intervals revealed that the modal response latency of the nonserial CS conditions

\footnotetext{
*The research reported in this manuscript was supported, in part, by Biomedical Science Support Grant F-R-07035 and by Grant MH 16584 from the National Institute of Health. which were awarded to the author.
}

occurred approximately $2.5 \mathrm{sec}$ after onset of the 16-sec CS-US interval. The responses to the two-component serial groups, surprisingly, peaked $10.5 \mathrm{sec}$ after the onset of the CS.US interval. $2.5 \mathrm{sec}$ after the onset of the second stimulus in the sequence. Seventy-five percent of the avoidances in the serial conditions occurred to S2 while only $30 \%$ of the responses occurred during the same time period for the nonserial conditions. The combined serial conditions also reliably produced more avoidances than the combined nonserial CS conditions. Statistical differences between the two nonserial conditions or between the two serial conditions were not obtained. The findings of two additional experiments reported in this study suggest that the effects of the serial groups were not due to the increased number of stimulus onsets and offsets for these conditions or to the shorter CS durations resulting from the division of the serial conditions into two distinctive segments

The present investigation was designed to replicate part of the Levis and Stampfl study with a different strain of rats and to increase the number of different stimuli incorporated within the $\mathrm{CS}$ sequence. The question of whether or not the time characteristics of the CAR would be further altered by the introduction of yet another stimulus into the CS sequence was of prime interest. Two experiments were run. The first compared the effects of nonserial and serial CS presentations while the second compared nonserial and serial compound CS presentations. In both of these experiments the serial conditions were divided into two groups, one with a two-component stimulus sequence and the other with three components.

\section{EXPERIMENT 1}

Subjects

The Ss were 72 experimentally naive male hooded rats bred in the University of Iowa's Department of Psychology colony. They ranged in age from 108 to 120 day's and in weight from 302 to $380 \mathrm{~g}$.

\section{Apparatus}

The shuttlebox apparatus used is described in Experiment 3 of the Levis and Stampfl paper. Programming equipment enabled the activation of six $71 / 2 \cdot \mathrm{W}, 115 \cdot \mathrm{V}$ candelabra screw-base lamps, a tone $(1.200 \mathrm{~Hz})$, and a buzzer. Apparatus was housed in a sound-attenuated IA chamber, and white noise produced by a Grason-Stadler generator (Model 901B) served as background noise. Measurements made by a Hermon Hasner Scott, Inc., sound level meter (Model 410-A, setting slow speed, scale B) indicated the ambient noise in the test room to be $63 \pm 1 \mathrm{~dB}$. When the tone or buzzer was activated, the sound pressure level rose to $64 \mathrm{~dB}$. Measurement was made $6 \mathrm{in}$. above the grid of the box centered on the midpoint of the apparatus.

\section{Groups}

Eighteen Ss were assigned unsystematically to each of four groups. Two of these groups involved nonserial CS manipulations and two involved serial manipulations. For one of the groups in the nonserial CS condition (S1), only one of the manipulated CSs was present during the designated CS-US intervals, while three different CSs were presented simultaneously throughout the CS-US interval for the other condition (S1S2S3). For one of the serial manipulations (S1/S2), two CSs were presented, with the onset of S2 occurring at the midpoint of the CS-US interval dividing the interval into two equal time segments. For the other group (S1/S2/S3), three CSs were presented sequentially so as to divide the CS-US interval into three equal time segments. For both of the serial conditions, the onset of a new stimulus in the chain resulted in the termination of the previous stimulus. The type (tone, flashing lights, buzzer) and order of CS presentation were appropriately counterbalanced within each group.

\section{Procedure}

Each $S$ was given a $30-\mathrm{min}$ adaptation period to the apparatus prior to the start of the first trial. A delayed conditioning procedure was used with a CS.US interval of $18 \mathrm{sec}$. The shock source was set to produce $1 \mathrm{~mA}$ of current. An escape response terminated both the CS and US. while an avoidance response terminated the CS and prevented US onset. The stimulus 


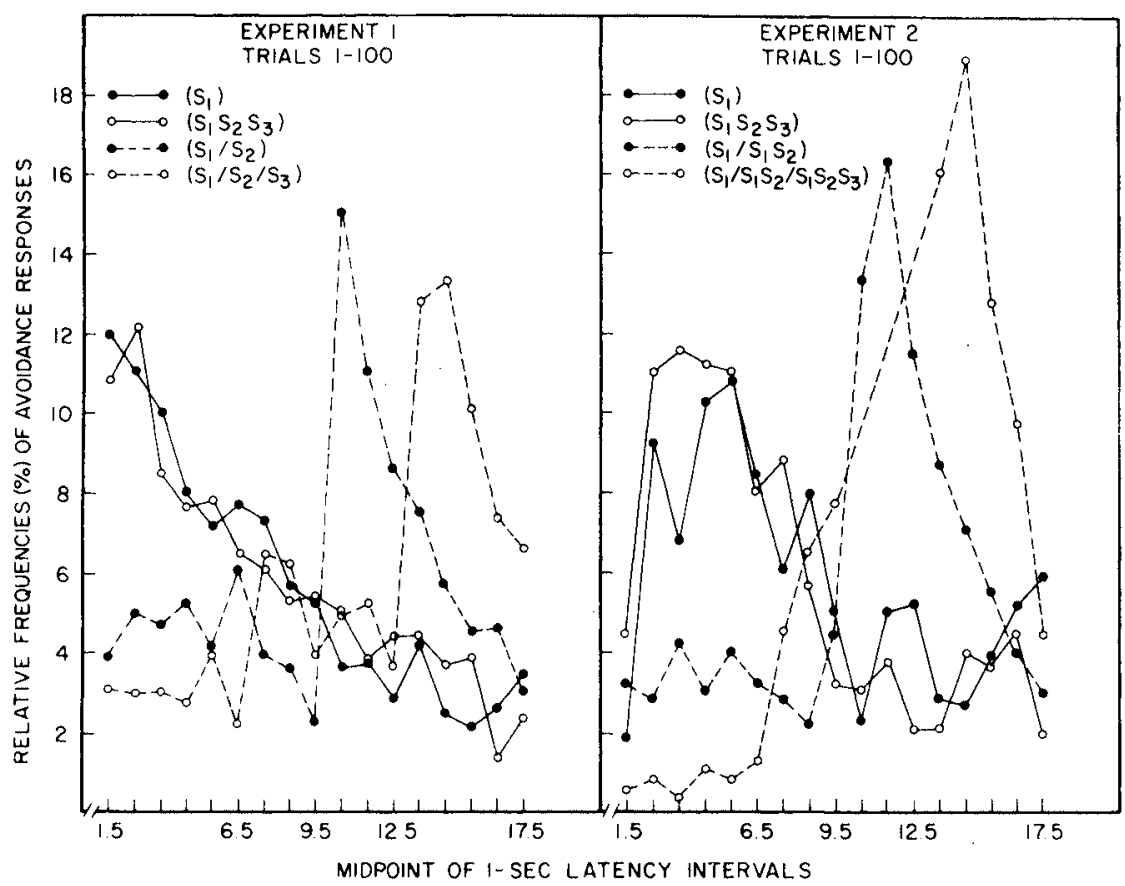

Fig. 1. Frequency distribution of the percentage of avoidance responses for the $C S$ conditions presented in Experiment 1 (left side) and Experiment 2 (right side) plotted in 1 -sec class intervals.

duration for each of the components in Groups S1/S2 and S1/S2/S3 was $9 \mathrm{sec}$ and $6 \mathrm{sec}$, respectively. In the case of Group $S 1 / S 2$, S2 could be avoided if a response occurred prior to the 9 th sec. In the case of Group S1/S2/S3, S2 and S3 could be avoided if a response occurred prior to the 6 th sec, while S3 would be the only CS avoided if a response occurred between the 6th and 12 th sec. Each $S$ was given 100 consecutive acquisition trials in a single training session. The length of the intertrial interval averaged $60 \mathrm{sec}$ (50-60.70 sec randomized). The order of running Ss was determiried randomly.

\section{Results}

Eight Ss were discarded and replaced on the next run because of apparatus failure. The discarded Ss were fairly evenly distributed among CS conditions. The left side of Fig. 1 provides a graph of the frequency distribution of avoidance latencies in $1-\mathrm{sec}$ class intervals for each of the CS conditions for all trials. These data replicated the findings of Levis and Stampfl in that the nonserial CS conditions' modal response peaked close to the onset of the CS-US interval while the mode in Serial Condition S1/S2 peaked closely to the onset of S2. With the introduction of three stimuli in the serial sequence, modal responding occurred shortly after the onset of S3. The majority of avoidances occurred to the first $9 \mathrm{sec}$ of the CS-US interval for nonserial Groups S1 $(68 \%)$ and S1S2S3 (65\%). For serial condition S1/S2 the majority of responses (63\%) occurred after the onset of $\mathrm{S} 2$ $(9-17 \mathrm{sec})$, while for Group S1/S2/S3 the majority (54\%) occurred after the onset of S3 $(12.17 \mathrm{sec})$. The time characteristics of the avoidance response for the various CS conditions tended to be relatively consistent throughout training.

The mean number of avoidances for Groups S1, S1S2S3, S1/S2, and S1/S2/S3 were $35.8,45.1,36.3$, and 37.7 , respectively. Contrary to expectations, none of these groups differed from each other statistically. Escape latencies also did not differ reliably among CS conditions with most responses occurring within 1 or 2 sec after shock onset.

\section{EXPERIMENT 2}

Subjects and Apparatus

The Ss were 90 experimentally naive male hooded rats. They ranged in age from 133 to 159 days and in weight from 310 to $360 \mathrm{~g}$. Reorganization of laboratory facilities resulted in the following changes in apparatus from the one used in the previous experiment. Ss were run in one of two shuttleboxes, the first being the same as that used in Experiment 1, with the second being modeled after the dimensions of the first. The two boxes were housed separately in sound-attenuating IA chambers. White noise was not used as a background stimulus, and the buzzer was replaced by white noise as one of ine CSs. Tone frequency was $4,000 \mathrm{~Hz}$. Ambient noise level measured by a General Radio sound level meter (Model 1551-C) was $60 \pm 1 \mathrm{~dB}$ (setting: C, slow speed) for Box 1 and $68 \pm 1 \mathrm{~dB}$ for Box 2 . Measurement was made 2 in. above the grid of one of the compartments centered on the midpoint of the apparatus. After activation of tone or white noise, noise level in the compartment increased $10 \pm 1 \mathrm{~dB}$. Programming equipment was housed in a separate room.

Groups and Procedure

Eighteen $\mathrm{Ss}$ were assigned unsystematically to each of five groups. The experimental groups, Groups $\mathrm{S} 1$, S1S2S3, S1/S1S2, and S1/S1S2/S1S2S3, replicated the same $\mathrm{CS}$ conditions as employed in Experiment 1 except that a serial compound procedure was substituted for the serial conditions. The difference being that with the onset of S2 or S3, the preceding stimulus or stimuli in the sequence continued to remain on for the entire CS-US interval instead of immediately terminating. All other aspects of the precedure were identical to the ones employed in the previous experiment. A noncontingent control condition, Group NCS, was also run. This group received shock on an average of $30 \mathrm{sec}$ (20-30-40 sec randomized) following the termination of a three-component serial compound condition (S1/S1S2/S1S2S3). Results

Seventeen Ss were discarded because of apparatus and procedural failures. The discarded Ss were fairly evenly distributed among CS conditions and were replaced on the next run. The right side of Fig. 1 provides a graphic representation of the distribution of avoidance latencies in the same manner as described in Experiment 1. These results are quite similar to the latency finding in the first experiment. Looking at the total avoidance responses, the majority occurred to the first $9 \mathrm{sec}$ of the CS-US interval for Groups S1 (61.4\%) and S1S2S3 (66.0\%). For serial condition S1/S1S2, the majority of responses (76.4\%) occurred after the onset of $\mathrm{S} 2$, and for Condition S1/S1S2/S1S2S3, the majority of responses $(67.5 \%)$ occurred after the onset of S3. Again, the time characteristics of the avoidance response remained relatively consistent throughout training.

A comparison of the various CS conditions on total number of avoidances did produce a statistical difference $(F=3.05, \mathrm{df}=3 / 68, \mathrm{p}<.05)$. The mean number of avoidances for Groups $\mathrm{S} 1$, S1S2S3, S1/S1S2, and S1/S1S2/S1S2S3 were 23.6, 25.8, 40.7, and 50.1, respectively. Group S1/S1S2 differed reliably from Group SI $(\mathrm{t}=1.9, \mathrm{df}=1 / 35$, $\mathrm{p}<.05)$, and Group S1/S1S2/S1S2S3 differed reliably from both Group S1 
$(t=2.7, \quad d t=1 / 35, \quad p<.011$ and Group S1S2S: $\quad(t=2.2 . \quad d f=13.5$. $\mathrm{p}<.01)$. A comparison between Groups $S 1$ and SIS2S3, and between Groups S1/S1S2 and S1/S1S2/S1S2S3 did not produce a reliable difference. Escape latencies did not differ reliably between groups. with most responses occurring 1 or $2 \mathrm{sec}$ after shock onset. Ss in Group NCS made few responses to the $\mathrm{CS}$, as indicated by their mean of 5.7 and median of 1.0 .

\section{DISCUSSION}

An analysis of the time characteristics of the avoidance response between serial and nonserial $C S$ conditions produced comparable results in both experiments of this study and are in agreement with the latency data reported by Levis and Stampfl. although strain and procedural differences existed between studies. The findings indicate that $\mathrm{Ss}^{\prime}$ avoidances tend to be delayed when the CS-US interval is equally divided into two or more discriminably different CS segments. Apparently the response is delayed until after the onset of the last stimulus in the sequence and appears to be so throughout training. The delay in responding can be interpreted as a result of a decrement in generalization of fear from the last stimulus of the $C S$ sequence to the stimulus immediately preceding it. The decrement is believed to increase as the stimulus difference between these two stimuli increases. This hypothesis is outlined in detail elsewhere (Levis \& Stampfl, in press).

It was further found that a straight scrial CS presentation did not enhance avoidance responding (Experiment 1) while a serial compound CS did (Experiment 2). In both experiments a three-component compound CS did not differ reliably from a one-component $\mathrm{CS}$ in total number of avoidances, nor did a three-component serial condition differ from a two-component condition.

Although it should be noted that in the comparison between be noted that in the comparison between the two and three serial CS conditions just reported, the conditions differed both in number of $\mathrm{CS}$ components manipulated and the time length of each sequence. The latter difference occurred because of the decision to hold the total CS-US interval constant for all groups. Further work on sequential CS presentation appears warranted.

\section{REFERENCES}

LEVIS, D. J., \& STAMPFL, T. G. Effects of serial CS presentation on shuttlebox avoidance responding. Learning \& Motivation, in press.

RAZRAN, G. Empirical codification and specific theoretical implications of compound-stimulus conditioning: Perception. In W. F. Prokasy (Ed.), Classical conditioning: A symposium. New York: Appleton-Century-Crofts, 1965. Pp. 000-000.

STAMPFL, T. G., \& LEVIS, D. J. The essentials of implosive therapy: A learning-theory-based psychodynamic behavioral therapy. Journal of Abnormal Psychology, 1967, 72, 496-503.

\section{Serial CS presentation and one-way avoidance conditioning: A noticeable lack of the delay in responding*}

\author{
DONALD J. LEVIS, SALLY ANN BOUSKA, \\ JOSEPH B. ERON, and MICHAEL D. MCILHON \\ University of Iowa, lowa City, Iowa 52240
}

An experiment was reported that compared seven different CS conditions on the acquisition and extinction of avoidance responses in a one-way situation. Three of the groups received nonserial CS manipulations comprising one, two, or three components; two received straight serial CS presentations (e.g., S1 followed by S2), comprising either two or three components; and two received serial compound CS conditions (e.g., S1 followed by S1S2) comprising either two or three components. The groups did not differ reliably on five different acquisition indices. The extinction data did produce reliable differences between combined serial and nonserial CS conditions with the serial CS conditions producing greater resistance to extinction. Reliable differences were not found between serial and serial compound conditions or between number of CS components. The tendency for the avoidance response to be delayed for the serial CS conditions which is characteristic of shuttlebox data was noticeably absent in the study. The majority of responses for both serial and nonserial CS conditions occurred close to the onset of the CS-US interval. A discussion illustrating the differences between one-way and shuttlebox avoidance situations was made.
Baker (1968) in a recent review article on compound stimuli noted that a renewed interest has developed in the properties of serial or sequentially ordered conditioned stimuli (e.g., light followed by a tone). The small, but consistent, body of literature in the infrahuman avoidance-conditioning area suggests that serial CS presentation enhances avoidance responding when compared with nonserial CS procedures. This finding occurs in both a shuttlebox (Kostanek \& Sawrey, 1965; Levis, 1970b; Levis \& Stampfl, in press; Oliverio, 1967; Stampfl, 1961) and in a one-way avoidance situation (Levis, 1966a, b).

Recently, Levis (1970b) and Levis and Stampfl (in press) reported that the time characteristics of the avoidance response also differs between serial and nonserial CS conditions. Using a shuttlebox situation, these investigators found that the avoidance-response latencies of Ss presented the serial CS conditions tended to be delayed until after the onset of the last stimulus segment introduced in the sequence. This was not the case for the nonserial CSSs who tended to avoid shortly after the onset of the CS-US interval. This tendency for serial CS Ss to delay responding is similar in some respects to the phenomena reported when a warning stimulus is superimposed on a Sidman avoidance schedule (Field \& Boren, 1963; Sidman, 1955). In this latter situation Ss also tended to delay responding until the onset of the warning stimulus rather than responding to the period preceding the warning stimulus.

Whether or not the time characteristics of the avoidance response in the one-way situation is also affected by serial CS presentation is not yet clear. The present study is an attempt to provide data on this question and to explore further the effects of different serial CS procedure on the frequency of avoidance responding. SUBJECTS

The Ss were 96 experimentally naive male hooded rats bred in the University of lowa's Department of Psychology colony. They ranged in age from 102 to 120 days. APPARATUS

The apparatus, a modified Mowrer-Miller one-way box, was divided into two equal compartments by an inverted guillotine

\footnotetext{
* The research reported in this manuscript was supported. in part, by Biomedical Science Support Grant FR-07035 and by Grant $\mathrm{IHH}$ 16584. from the National Institute of Health. which were awarded to the first author. This research was also conducted while the latter three authors were participants in the Lndergraduate Rescarch Participation Program of the Department of Psychology, University of Iowa. This program was supported by Grant GY 3456 from the National Science Foundation.
} 